\title{
Teledermatology: current perspectives
}

This article was published in the following Dove Press journal:

Smart Homecare Technology and TeleHealth

5 October 2017

Number of times this article has been viewed

\author{
João Antonio de Queiroz \\ Oliveira ${ }^{1,2}$ \\ lago Souza Wolff ${ }^{1,2}$ \\ Laura Defensor Ribeiro 1,2 \\ Maíra Viana Rego Souza e \\ Silva ${ }^{1,2}$ \\ Leonardo Teixeira \\ Domingos Silva ${ }^{1,2}$ \\ Milena Soriano Marcolino',2 \\ 'Telehealth Center, University \\ Hospital, Universidade Federal \\ de Minas Gerais, Belo Horizonte, \\ Minas Gerais, Brazil; ${ }^{2}$ Department of \\ Internal Medicine, Medical School, \\ Universidade Federal de Minas Gerais \\ Belo Horizonte, Minas Gerais, Brazil
}

Correspondence: Milena Soriano Marcolino

Telehealth Center, University Hospital, Avenida Professor Alfredo Balena, II0, $I^{\circ}$ andar, Ala Sul, Sala 107 - Santa

Efigênia, Belo Horizonte, Minas Gerais, CEP 30130-100, Brazil

Tel +55 3I 34099201

Email milenamarc@gmail.com
Purpose: The purpose of this study was to update the current status on accuracy, reliability, and clinical outcomes and establish barriers and perspectives of teledermatology strategies.

Methods: MEDLINE was searched to identify relevant studies published until April 2017, supplemented by references from the selected articles. Study search and selection were performed by independent reviewers. Quality assessment was performed.

Results: Of the 2,525 articles retrieved, 45 manuscripts ( 44 studies, 7,033 patients) were included in the review, 42 of them in developed countries. The studies were organized in three groups, according to their content: clinical outcomes $(n=16)$, diagnostic accuracy $(n=9)$, and diagnostic reliability $(\mathrm{n}=19)$. Teledermatology diagnosis is accurate, with sensitivity and specificity ranging from $73 \%$ to $97 \%$ and $73 \%$ to $83 \%$, respectively, when compared to face-to-face (FTF) diagnosis and/or histopathological results. The diagnostic agreement between teledermatologists and FTF dermatologists showed high variability, from fair (kappa 0.35) to almost perfect (kappa 0.91), but in most of the studies the agreement was almost perfect. Studies that used educational teledermatology strategies showed benefits in improvement of severity of skin conditions, adherence to therapy, and higher quality-of-life score; and anxiety reduction in patients with psoriasis, when compared to usual care. Overall, interventions focused on clinical outcomes showed at least similar results when compared to usual care. Interventions connecting patients to specialists or health care practitioners to specialists did not show statistical difference in the rate of healing, severity, and/or clinical evolution of skin conditions when compared to usual care, except for one study with methodological issues.

Conclusion: Overall, teledermatology demonstrated good performance in comparison to conventional consultations for diagnostic agreement and diagnostic accuracy. The evidence suggests there is no difference in clinical outcomes with teledermatology in most cases, but adequately powered studies for subgroups of skin conditions are needed.

Keywords: telemedicine, dermatology, review, health impact assessment

\section{Introduction}

Teledermatology is one of the most common applications of telehealth. The possibility of secure transmission of medical data and images using different devices, in situations where a health professional and a patient (or two professionals) are not in the same location, and the strong visual component of dermatology make this strategy very useful, mostly for patients in remote areas. ${ }^{1}$ It can be used for diagnosis, treatment, and follow-up of patients after a first dermatologist consultation, or to triage primary care cases and limit unnecessary referrals to dermatologists, ${ }^{2-6}$ reducing social costs related to patient travel, such as productive working hours and transportation expenses. ${ }^{1}$ 
The intervention can be used in three different modalities, according to how transmission and reception are performed: synchronous (real time), asynchronous (store-and-forward), or hybrid, a model that integrates elements of both modalities (high-resolution digital images are used in combination with videoconferencing). ${ }^{1,7}$ The asynchronous modality, in which users do not need to be connected at the same time, is more disseminated, as a consequence of lesser technology requirements and more affordable costs.

Before widespread implementation, however, we must assess the accuracy and reliability of teledermatology interventions, how it affects the clinical course of patients, and identify situations where they work best, as this information is highly relevant for informed decision making and planning.

We aim to update the status and establish the barriers and perspectives of teledermatology by systematically reviewing the most recent studies on clinical outcomes, reliability, and accuracy of telemedicine interventions compared to usual face-to-face (FTF) care in the diagnosis and treatment of dermatological affections.

\section{Methods}

\section{Search methods}

A literature search was conducted using MEDLINE through PubMed search engine. The search strategy was: ([dermatology OR dermoscopy OR skin OR “wound care"] AND [telemedicine OR mobile OR mHealth OR telehealth OR eHealth OR telecare]) OR (teledermatology OR teledermoscopy). The search was restricted to controlled trials (randomized and non-randomized), quasi-experimental studies, and observational studies in humans, published in the last 10 years (from January 1, 2007 up to the search date) and to the publication language (English, French, Spanish, Italian, and Portuguese). In addition, the reference lists of relevant articles were hand searched. The last search was performed on April 15, 2017.

\section{Inclusion criteria and study selection}

The inclusion criteria for this review were as follows: 1) participants were patients of any age or health care providers; 2) any kind of intervention using telemedicine tools (computerized systems for information exchange, videoconferencing, and exchange of information via telephone or other mobile devices, short message service, or through the Internet) and applications for clinical diagnosis support and treatment delivery; 3) clinical outcomes related to dermatology; and 4) studies investigating diagnostic accuracy or reliability, effectiveness, or clinical benefits of telemedicine intervention in dermatology.
Exclusion criteria were as follows: 1) studies in which intervention was for prevention purpose or if the intervention was online self-guided that did not incorporate professional health care feedback or guidance; 2) studies about feasibility, user acceptance, or usability that did not assess the impact in clinical outcome; and 3) studies that evaluated only patients or provided satisfaction or perceived benefits.

Three investigators (JAQO, MVRSS, and ISW) independently reviewed titles and abstracts of the search results to decide whether the full text should be examined according to the predefined inclusion and exclusion criteria. Abstracts that did not provide enough information for analysis of the intervention or the methodology regarding the inclusion and exclusion criteria defined in this review were retrieved for full-text evaluation. Subsequently, the investigators evaluated the full text of selected articles and determined study eligibility. Disagreements were solved by consultation with a fourth investigator (MSM). Lists of included and excluded articles are presented in Tables S1 and S2, respectively.

\section{Data extraction}

Studies were organized in three groups according to their focus or main outcome: 1) clinical outcomes; 2) diagnostic accuracy; and 3) diagnostic reliability. The characteristics of the studies (year and publishing journal, country and design), participants characteristics and methods description in control and intervention groups, and outcomes of intervention were extracted and summarized by three investigators (ISW, LDR, MVRSS) and revised by a fourth (JAQO).

\section{Quality assessment}

Methodological quality of the included studies was assessed using the Cochrane Risk of Bias Assessment Tool ${ }^{8}$ for studies focusing on clinical outcomes (by LTDS); the Quality Assessment of Diagnostic Accuracy Studies, second version $^{9}$ for diagnostic accuracy studies (by LTDS); and the Quality Appraisal of Reliability Studies (QAREL) ${ }^{10}$ for diagnostic reliability studies (by ISW). The quality results were revised by JAQO. Risk of bias graphs for clinical outcomes and diagnostic accuracy studies were performed using Review Manager (RevMan) software, version 5.3. (Nordic Cochrane Centre, The Cochrane Collaboration, Copenhagen, Denmark).

\section{Results}

A flow diagram of search and selection is shown in Figure 1. The database search resulted in 2,525 articles and one article was found through manual search. Of these, 2,381 were 


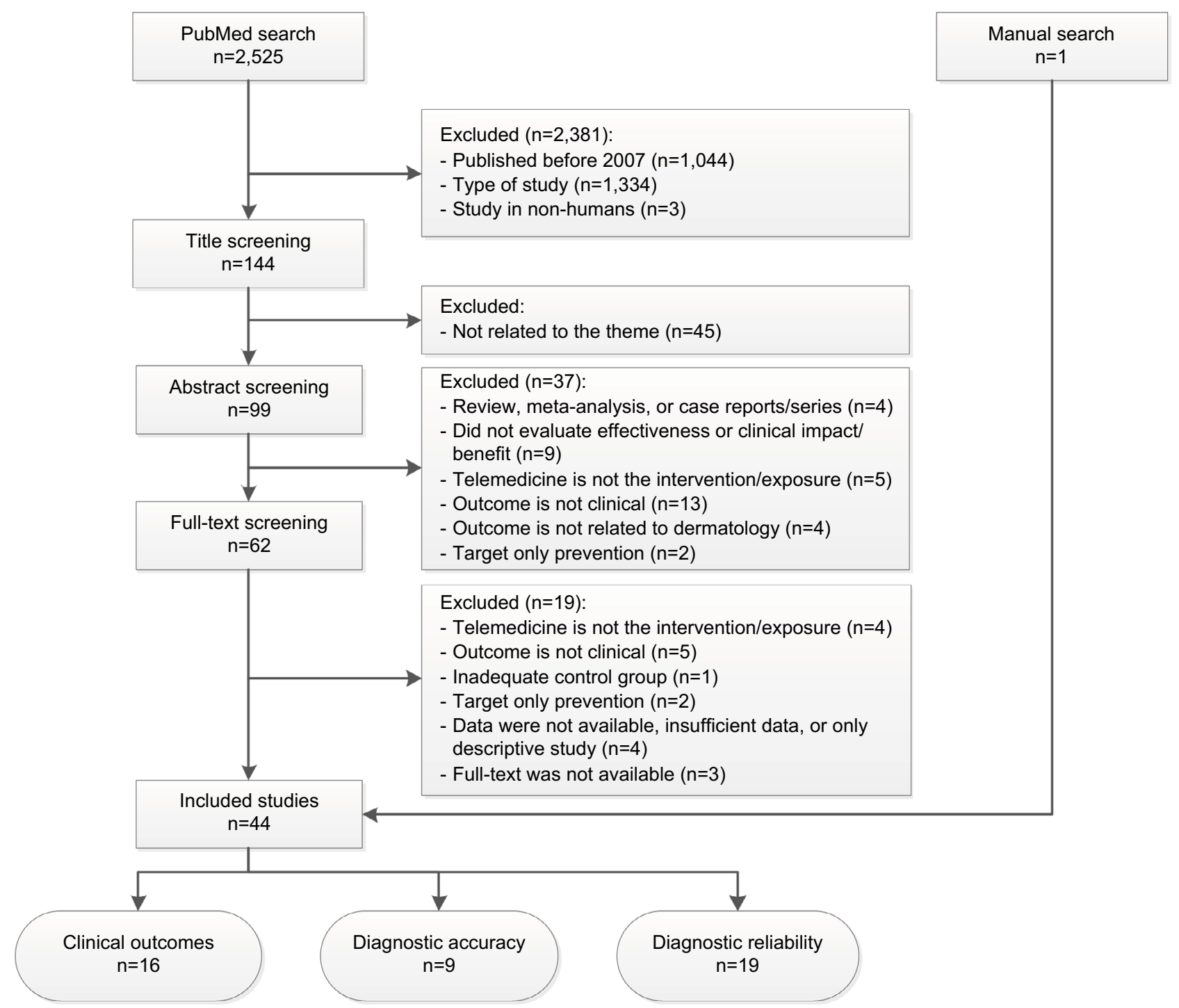

Figure I Flow diagram of study selection.

excluded after the limits were applied and 82 after title and/or abstract analysis. Therefore, 62 potentially relevant full-length articles were screened. From these, 44 manuscripts (43 studies) were included in the review and organized in three groups according to their content: clinical outcomes $(\mathrm{n}=16)$, diagnostic $\operatorname{accuracy}(\mathrm{n}=9)$, and diagnostic reliability $(\mathrm{n}=19)$ (Figure 1).

\section{Clinical outcomes}

Fifteen studies (sixteen articles) assessed clinical outcomes of teledermatology intervention. ${ }^{11-26}$ All studies were from high income countries. Six studies (seven articles) were from the United States, ${ }^{11,15,18,21,23-25}$ two from the Netherlands, ${ }^{17,22}$ and one from each of the following countries: Austria, ${ }^{16} \mathrm{Canada},{ }^{20}$ Denmark, ${ }^{26}$ Italy, ${ }^{12}$ Norway, ${ }^{13}$ Singapore, ${ }^{19}$ and United Kingdom. ${ }^{14}$ Eleven studies were randomized controlled trials ${ }^{11-16,18,20-25}$ (Table S3). One study used the intervention for both screening and follow-up. All the others ${ }^{24,25}$ used teledermatology for only follow-up.

A total of 2,208 patients were evaluated. There were similar proportions of both sexes when the studies were pooled. In most studies, the participants included were in the adult age, with the following exceptions: the mean age of participants was $>65$ years in two studies, ${ }^{20,26}$ one included adolescents and adults, ${ }^{16}$ one only children, and one with groups of children patients/parents of children and adult patients. ${ }^{22}$ Four studies focused on psoriasis lesions, ${ }^{12,14,15,17}$ three on atopic dermatitis, ${ }^{11,13,22}$ two on patients with acne, ${ }^{16,23}$ two on pressure ulcer, ${ }^{20,21}$ and two on chronic skin lesions. ${ }^{19,26}$ One study did not specify or presented the most frequent diagnosis, ${ }^{18}$ and in one study there was a wide variety of diagnoses. ${ }^{24,25}$ 
Ten studies used strategies involving store-and-forward teleconsultation, one included a hybrid model intervention, ${ }^{20}$ and in two studies the intervention was exclusively in synchronous modality. ${ }^{17,19}$ In most studies, the focus of the intervention was the patients, to determine the diagnosis and/or treatment. In only three of them the intervention was used to provide advice to another health practitioner. ${ }^{20,21,26}$

\section{Teledermatology interventions to determine the diagnosis and/or treatment}

Three studies used methods of telemedicine to enhance health education, adherence, and/or induce behavior change targeting mainly to improve quality-of-life (QoL), severity of the skin lesion, and/or healing time. Balato et al ${ }^{12}$ used daily mobile text messages in their intervention group providing reminders and educational tool for 12 weeks. The authors found statistically significant improvement of severity of skin lesions and QoL $(p<0.05)$, and also in adherence to therapy (days per week increased from 3.86 to 6.46 in the teledermatology group, $p<0.001)$ compared to usual care. Bundy et $\mathrm{al}^{14}$ also used an educational multimedia delivery format by accessing a web-based psoriasis-specific program for patients with emotional and psychological problems focusing, for example, in controlling the mood, stress, depression, and enhancing general management of psoriasis. There was statistical significant evidence that the intervention reduced anxiety (mean Hospital Anxiety and Depression Scale score reduced from $7.6 \pm 3.6$ at baseline to $6.1 \pm 3.5$ after intervention vs the control group, in which the mean score varied from $8.3 \pm 3.5$ at baseline to $8.1 \pm 4.4$ after follow-up, $p=0.004$ ) and improved QoL (Dermatology Life Quality Index was 6.6 \pm 4.2 before and 5.0 \pm 5.1 after intervention compared to usual care 7.4 \pm 4.4 before and 7.7 \pm 4.5 after follow-up, $p=0.042$ ).

Nine studies found teledermatology equivalent or no statistical difference to usual care using specific lesion validated scales to measure the severity and/or clinical evolution or evaluating the QoL and costs. ${ }^{11,15-19,22-25}$ Fruhauf et al $^{16}$ assessed a teledermatology invervention which involved sending facial images to a specialist and receiving treatment and management instructions within 24 hours. Even though Fruhauf et al verified similar remission rates of acne in the intervention and comparison groups (delta Global Acne Severity Scale scores of 2.25 and 2.0, respectively), the intervention group experienced less adverse reactions to isotretinoin therapy $(66.7 \%$ vs $75 \%, p=0.55)$. Oostveen et $\mathrm{al}^{17}$ found evidence of higher QoL scored using a Dutch version of the Children's Dermatology Life Quality Index in children with psoriasis that received teleconsultation by video call replacing one visit per week of the regular day care in FTF consultations compared to those patients who received only regular day care (6.1 vs $4.1, p=0.25)$. Besides clinical equivalence, Seghers et $\mathrm{a}^{19}$ also found positive results for other outcomes in the teledermatology group. The total patient turnaround time (calculated for the teledermatology group from the time of setting up the equipment until the end of the telemedicine consultation session, and for the control group from the time the patient left the ward until their return to the ward) was $90 \%$ lower in the group of patients that were sent to teledermatology consultation than those who received usual FTF care (23 vs 240 minutes).

In Bergamo et al's study, ${ }^{13}$ the intervention included a web-based program. Parents of eczema-diagnosed children had access to the program to fill a predesigned form to classify and rate the extent and severity of the eczema, based on the information sent, and a specialist provided treatment advice. The authors did not detect any statistical significant difference in clinical outcomes, self-management behavior, and costs between intervention and usual care groups, implying that teledermatology had no effect of supplementing traditional treatment for dermatitis in children with webbased consultations. However, they stated that the study did not have adequate statistical power, being unsupported to conclude that web consultations have no effect on clinical outcomes and resources use. ${ }^{13}$

Also, the teledermatology consultation showed an estimated total cost $56 \%$ lower than the usual consultation. Both Oostveen et $\mathrm{al}^{17}$ and Seghers et a ${ }^{19}$ studies were the only ones in which the intervention was synchronized.

\section{Teledermatology interventions to provide advice to another health practitioner}

One study showed evidence that teledermatology was better than usual practice. Zarchi et $\mathrm{al}^{26}$ studied the effectiveness of the use of a secure web-based program in collecting data of patients with chronic wounds that subsequently were sent to a team of wound-care experts, which provided a treatment strategy to home-care nurses and compared to usual care. In this study, the authors found that the adjusted hazard ratio (HR) of healing was significantly higher in the teledermatology group compared to the conventional care group (adjusted HR 2.19, 95\% confidence interval [CI] 1.15-4.17, $p=0.017){ }^{26}$

Stern et $\mathrm{al}^{20}$ assessed the clinical impact of teledermatology in a two-phase implementention of intervention: the first phase focused on training the facility staff in the assessment, digital imaging of the lesion, and standardized treatment by a senior nurse with expertise in skin and wound care; and the 
second phase involved remote support by a multidisciplinary wound-care team. No statistical difference was observed in the rate of healing between intervention and usual care, but some evidence of cost reduction in direct costs was found, even though this estimation was subject to uncertainty.

Terry et $\mathrm{al}^{21}$ assessed the cost-effectiveness of teleconsultations involving the tele-examination of digital images of pressure ulcer lesions or nonhealing surgical wounds by specialists who further proposed a management strategy. The authors compared three groups; two of them used storeand-forward teleconsultation (group A exclusively used teledermatology and group $\mathrm{C}$ used teledermatolgy in addition to usual care). The time to heal in intervention group was $51 \pm 34$ days in group $A$ and $35 \pm 25$ days in group $C$ versus $30 \pm 17$ days in group B. The mean of total cost/patient in group $A$ was $\$ 4,021.84$ and in group $C \$ 2,595.68$ versus $\$$ $1,937.01$ in group B. ${ }^{21}$

\section{Study quality}

Most of the studies were considered to have high-risk potential for bias, predominantly related to the design applied (Figures 2 and 3).

\section{Diagnostic accuracy}

Nine studies focused on diagnostic accuracy analysis of teledermatology. ${ }^{27-35}$ Studies were predominantly from high income countries. Three studies were from the United States, ${ }^{30,34,35}$ two studies from Germany, ${ }^{27,28}$ and one from each of the following countries: Australia, ${ }^{29}$ South Korea, ${ }^{31}$ and New Zealand..$^{32}$ There was one study performed in Brazil,,$^{33}$ which is an upper middle income country (Table S4). All studies focusing on accuracy limited the teledermatology intervention to the triage scenery.

A total of 2,212 patients were evaluated. There was a variety of participants between the studies, with predominance of female sex in two studies, ${ }^{32,33}$ only male patients in two studies, ${ }^{27,31}$ and no participant description in two other studies. ${ }^{28,30}$ Participants' age also varied and the range included children to older adults. In all studies, teledermatology intervention was used for the treatment.

In one randomized study, ${ }^{29}$ patients were predominantly female in the comparison group and male in the intervention group. There were higher rates of positive skin history in the intervention group, but only minimal differences were reported, suggesting that this differences was not clinical significant. Although the authors reported that there were only minimal differences between the groups, no statistical comparison was presented.

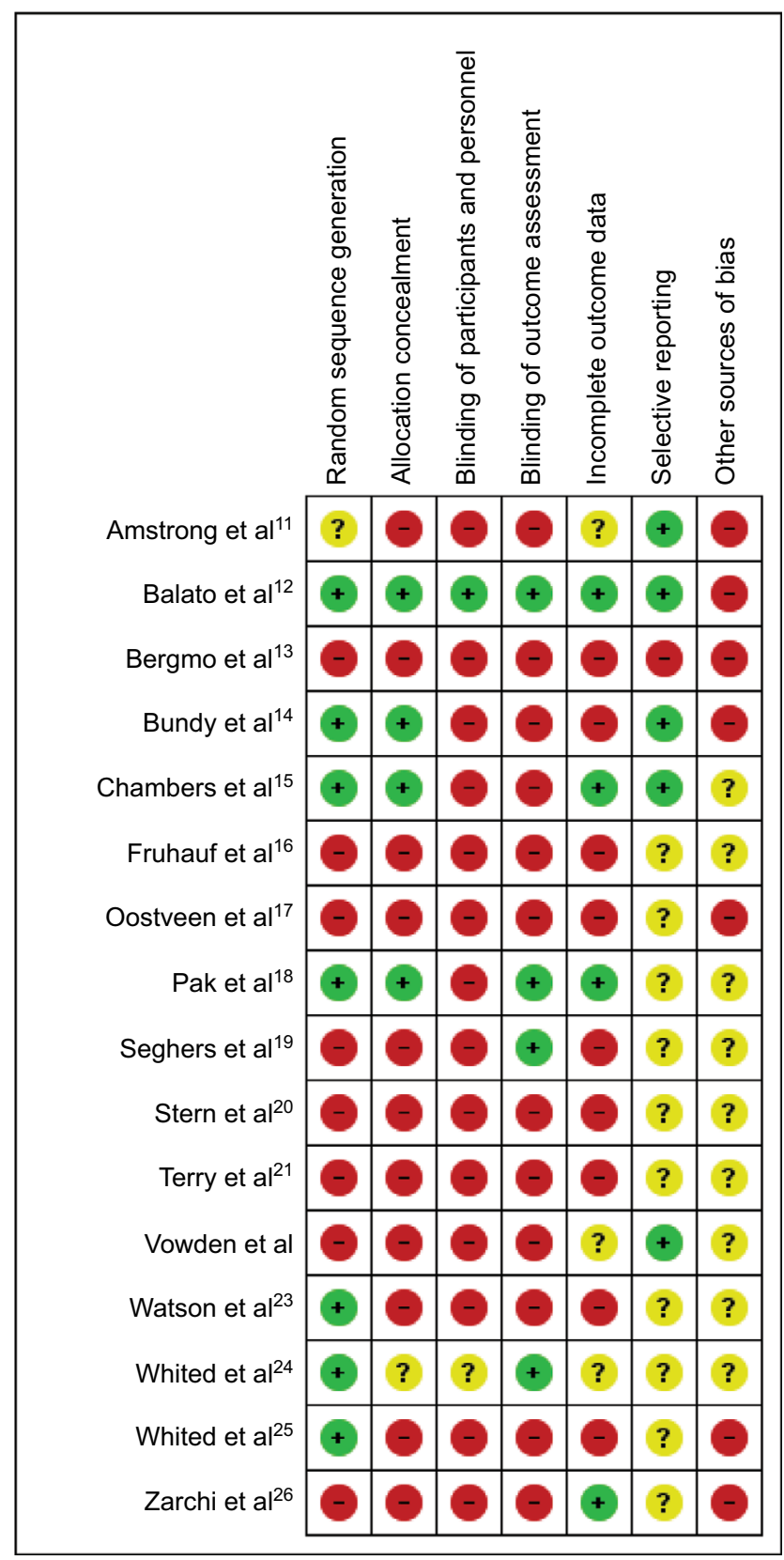

Figure 2 Risk of bias summary of studies that assessed clinical outcomes.

Six studies ${ }^{27,29-33}$ compared teledermatology to FTF evaluation for the diagnosis or examination of skin lesions and, of these, three studies s $^{30,32,33}$ also compared the teledermatology intervention to histopathologic examination, including one study $^{32}$ that only made this comparison for those cases when the histopathologic result was available. In only one study, the intervention did not involve the examination of photographs of the lesions by teledermatologists. Maier et $\mathrm{al}^{28}$ aimed to evaluate the diagnostic accuracy of a mobile application that uses an algorithm to propose a diagnosis and compare it to histopathological results. 


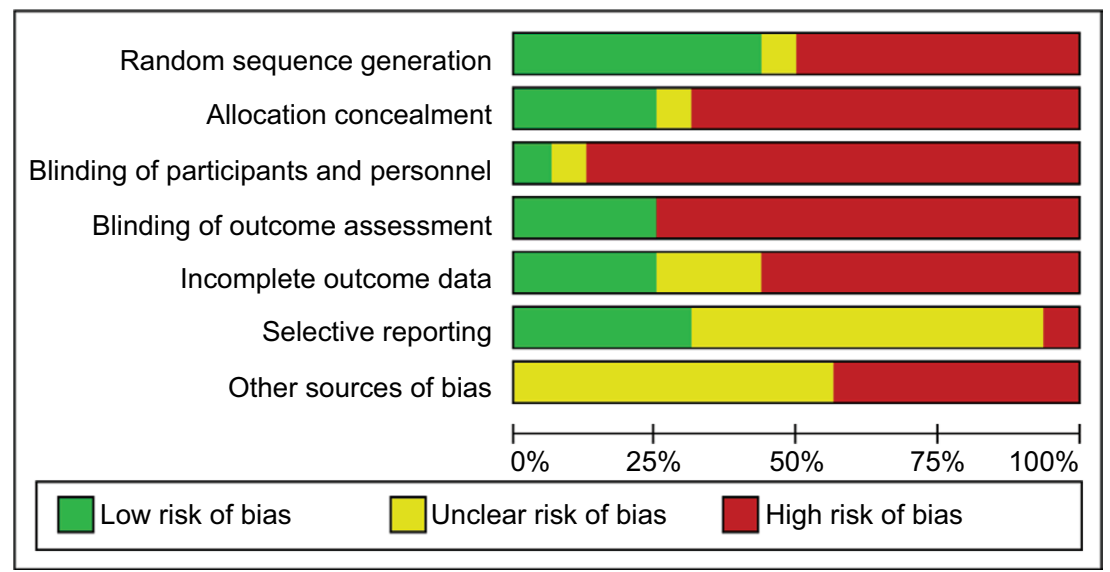

Figure 3 Risk of bias graph of studies that assessed clinical outcomes.

Two studies reported that teledermatology was not equivalent ${ }^{35}$ or even inferior to $\mathrm{FTF}^{34}$ Warshaw et $\mathrm{al}^{35}$ compared FTF consultation to teledermatology in three scenarios (using macro images only, macro images plus polarized light dermoscopy images, and macro images plus contact immersion dermatoscopy) for the assessment of diagnostic and management accuracy analyzing pigmented lesions. In all scenarios, telediagnosis showed inferiority to FTF diagnosis (accuracy $64.0 \%-67.0 \%$ versus $80.3 \%-80.8 \%$ ), but the management plan was at least equivalent. ${ }^{35}$ Another study from the same group of investigators, but analyzing nonpigmented lesions in two scenarios (using macro images only and macro images plus polarized light dermoscopy images), found worse results of telediagnosis when compared to FTF diagnosis (accuracy $59.5 \%-64.7 \%$ vs $76.1 \%-76.0 \%)^{34}$

In all the other studies, teledermatology diagnosis achieved at least an acceptable level of concordance to the FTF diagnosis and/or histopathological results. Baumeister et $\mathrm{al}^{27}$ compared tele-examination to FTF examination analyzing a subjective grading scale and score for detection of minimal skin lesions in 100 male metal workers exposed to cutting fluids. Although the authors did not assess the sensitivity and specificity of the telemedicine intervention, they reported no difference between the methods. ${ }^{27}$

Manahan et $\mathrm{al}^{29}$ assessed the accuracy of teledermatology for melanoma diagnosis in two groups of patients, one that received detailed specific instructions for skin self-examination $(n=25)$ and the other that did not receive those specific instructions for examination $(\mathrm{n}=24)$. The telediagnosis intervention in both groups was compared to FTF clinical skin examination performed within 3 months after the image of the lesion was sent to the teledermatologists. The sensitivity of telediagnosis in those patients that received detailed instructions was high at the patient level ( $82 \%$ ), but decreased to $42 \%$ when the lesion was used as denominator in the analysis. As justification for this difference, the authors hypothesized that at the FTF consultation, if the patients had observed at least one worring lesion, the physician might have done a whole body examination, what may have increased the identification of other melanoma lesions. The concordance between the telediagnosis and the FTF diagnosis achieved an almost perfect level (kappa 0.90). ${ }^{29}$

Shin et $\mathrm{al}^{31}$ analyzed the three most frequent lesion categories from 100 male army patients. The sensitivity of teledermatology diagnosis was high for eczema and viral warts categories ( $78 \%$ and $88 \%$, respectively) when compared to FTF diagnosis, but was lower $(61 \%)$ for fungal infections. The concordance, however, was statistically significant between teledermatology and FTF diagnosis (mean kappa $0.73 \pm 0.06$ ).

The studies that assessed the accuracy of teledermatology using histopathological results as reference standard showed good sensitivity and specificity. The number of images of skin lesions assessed varied from 64 to 491 . The sensitivity of teledermatology diagnosis ranged from $73 \%$ to $97 \%$, and the specificity ranged from $73 \%$ to $83 \% .{ }^{28,30,32,33}$ Results comparing FTF and histopathological diagnosis were slightly better than the teledermatology diagnoses by Maier et $\mathrm{a}^{28}$ and Tan et al, ${ }^{32}$ but no statistical difference was found by the former and there was no direct comparison of results between telediagnosis and FTF diagnosis by the latter.

\section{Study quality}

Overall, the evidence regarding accuracy had a low risk of bias. Most of the studies were applied on very specific populations and patient selection could not have represented the general population (Figures 4 and 5). 


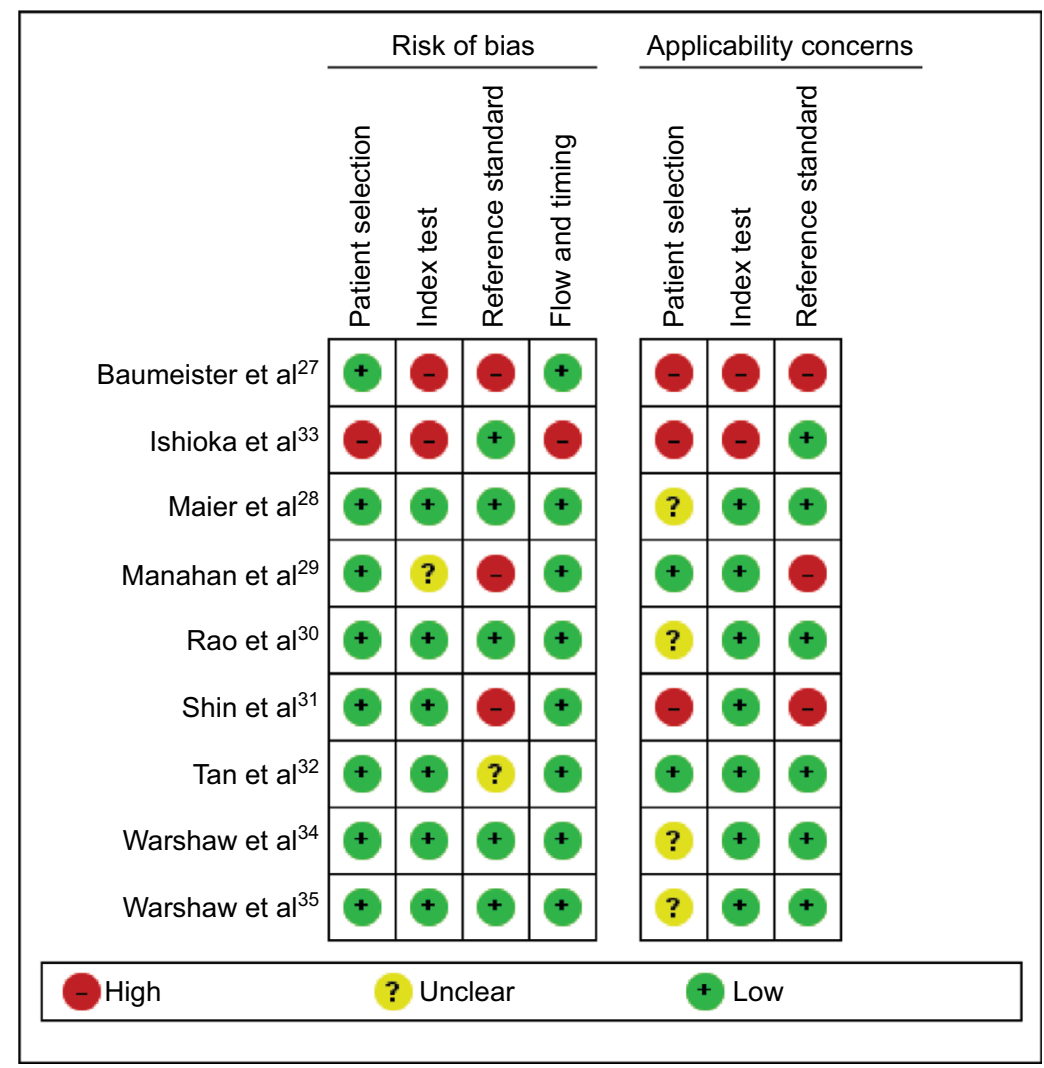

Figure 4 Methodological quality graph of studies that assessed diagnostic accuracy.

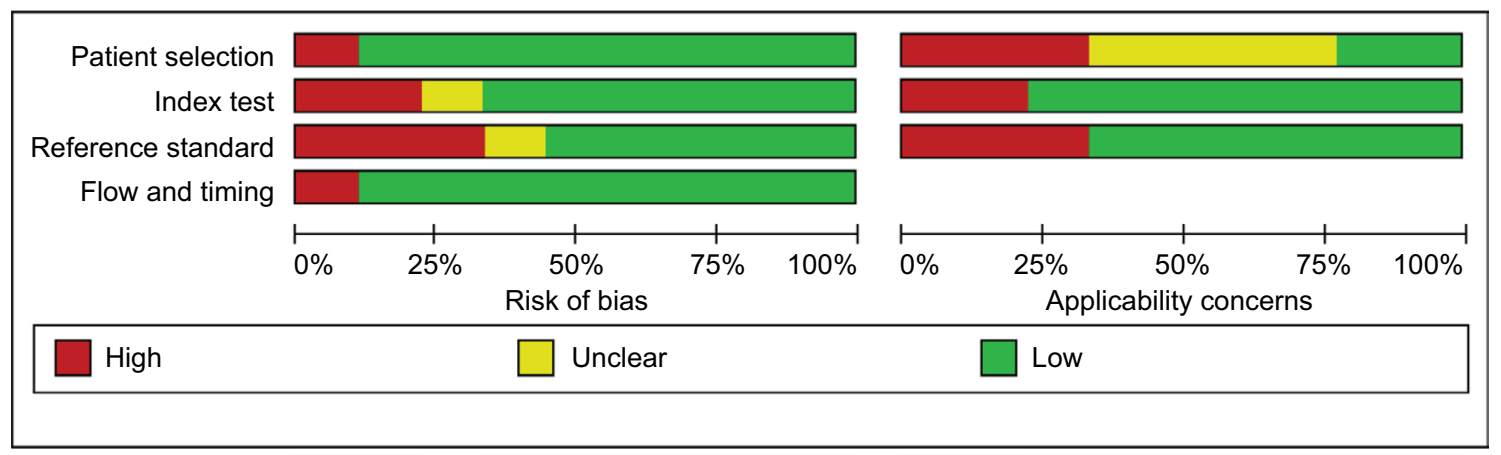

Figure $\mathbf{5}$ Methodological quality summary of studies that assessed diagnostic accuracy.

\section{Diagnostic reliability}

Eighteen studies (19 articles) focused on the assessment of the reliability of teledermatologic interventions..$^{5,7,36-52}$ Studies were predominantly from high income countries. Six studies were from the United States, ${ }^{5,36,37,42,43,45}$ four from Spain, ${ }^{7,40,48,51,52}$ two from Italy, ${ }^{38,39}$ one from Austria, ${ }^{41}$ one from Germany, ${ }^{49}$ one from Sweden, ${ }^{44}$ and one from Panama. ${ }^{50}$ Two studies were multicentric: one from Ghana and the United States, ${ }^{47}$ and one from Austria and Italy ${ }^{46}$ (Table S5). All the studies focusing on reliability used teledermatology intervention in the triage scenery.
The participants' characteristics were highly variable between the studies. There was a predominance of female sex in six studies, ${ }^{5,36,40,45,46,50}$ male predominance in two studies, ${ }^{41,43}$ and no information about sex in nine studies. ${ }^{7,37-39,42,47,49,51,52}$ Participants' age also varied, ranging from infants to elderly patients. Three studies focused on pediatric patients. ${ }^{42,44,48}$ In the studies analyzed, there was no difference in participants' description between control and intervention groups, as both groups were composed of the same subjects.

A total of 2,613 patients were evaluated. One study examined patients with psoriasis, ${ }^{41}$ three examined hypo 
or nonpigmented lesions, ${ }^{5,34,39}$ two examined pigmented lesions, ${ }^{35,38}$ one used split-thickness skin and wound from epidermolysis bullosa patients, ${ }^{49}$ one studied patients with pressure ulcer, ${ }^{43}$ and one analyzed hospitalized children with cutaneous rashes. ${ }^{42}$ The remaining studies encompassed multiple skin conditions. . $^{736,37,40,45-47,50-52}$

Twelve studies analyzed the reliability by kappa statistics..$^{5,36,38-42,44-46,48,50}$ From these, one study compared teledermatology and FTF diagnosis to histopathological results, ${ }^{39}$ one compared both groups to teledermatology and FTF diagnosis to the definitive diagnosis, ${ }^{40}$ all the others considered FTF consultation as standard reference without histopathological confirmation for the diagnosis. In two studies focusing on reliability, teledermatology was used for advising another medical provider. ${ }^{48,52}$ All the others used the intervention for treatment by the dermatologist.

Fabroccini et al $^{39}$ investigated the concordance between clinical and dermoscopic diagnosis of teledermatology and FTF consultation to histopathologic diagnosis and found that telediagnosis presented lesser agreement than FTF diagnosis (kappa $0.44-0.45$ vs $0.52-0.70$ ). The interobserver agreement between the two teledermatologists was fair for clinical diagnosis (kappa 0.36) and moderate (kappa 0.44) for dermoscopic diagnosis. ${ }^{39}$ Ferrer et al compared the concordance of telediagnosis and FTF diagnosis to the final diagnosis, after presential consultation with all complementary examinations. Teledermatology showed an agreement higher than FTF diagnosis, achieving an almost perfect level (kappa 0.95 vs 0.60). ${ }^{40}$

Of studies that compared telediagnosis to only FTF diagnosis, using kappa statistics, the overall diagnostic agreement between teledermatologists and FTF dermatologists showed high variability, from fair (kappa 0.35$)^{36}$ to almost perfect (kappa 0.91), ${ }^{46}$ even though the majority of them (eight studies from 10) achieved substantial to almost perfect agreement. $5,38,41,42,44-46,48,50$ The agreement of management or therapy plan between both groups was only assessed by two studies, varying from moderate (kappa 0.57$)^{45}$ to almost perfect (kappa 0.86). ${ }^{46}$ The intra-observer diagnostic reliability was investigated by three studies (kappa ranged from 0.49 to 0.69$),{ }^{36,38,42}$ and the intra-observer management reliability by only one of them (kappa 0.58). ${ }^{38}$

Two studies used correlation to evaluate the concordance between teledermatology and FTF consultation. ${ }^{43,49}$ Rennekampff et al, ${ }^{49}$ assessing the reliability of photographic analysis of wound healing, detected excellent intra-reliability between the examiners ( $r 0.79,95 \%$ CI $0.61-1.00)$ and good inter-realibility between all four examiners and FTF consultation ( $r 0.67,95 \%$ CI $0.57-1.00)$. Hill et $a^{43}$ also reported good correlation between two modalities of telediagnosis and FTF diagnosis ( $r 0.76$ for telephone modality and $r 0.83$ for videoconference modality).

In four studies, the diagnostic concordance between teledermatology and usual care was compared by proportions of concordance. The percentages of agreement varied from 69\% to $92 \%$, demonstrating relatively good concordance. $7,37,47,51,52$

\section{Study quality}

Overall, the evidence for reliability had a low risk of bias. By the QAREL, the order of examination, intra-examiner blinding, and reference standard result blinding had a majority of "no" or "not applicable" answers. Unclear answers were provided mostly with respect to additional clue blinding and inter-examiner blinding. The studies by Osei-tutu et al, ${ }^{47}$ Romero et al, ${ }^{7}$ Romero Aguilera et al, ${ }^{51}$ Vano-Galvan et al, ${ }^{52}$ and Chung et $\mathrm{al}^{37}$ did not apply state-of-the-art statistical analysis of kappa coefficient (Table 1).

\section{Discussion}

The body of evidence presented here showed that overall, teledermatology diagnosis is accurate, with sensitivity and specificity ranging from $73 \%$ to $97 \%$ and $73 \%$ to $83 \%$, respectively, when compared to FTF diagnosis and/or histopathological results. The diagnostic agreement between teledermatologists and FTF dermatologists showed high variability, from fair (kappa 0.35) to almost perfect (kappa 0.91), but in most of the studies the agreement was almost perfect. Studies that used educational teledermatology strategies showed benefits in improvement of severity of skin conditions, adherence to therapy, and higher QoL score; and anxiety reduction in patients with psoriasis, when compared to usual care. Overall, the interventions focused on clinical outcomes showed at least similar results when compared to usual care.

Interventions connecting patients to specialists or health care practitioners to specialists did not observe statistical difference in the rate of healing, severity, and/or clinical evolution of skin conditions when compared to usual care, except for one study with methodological issues, which included patients with pressure ulcer lesions or nonhealing surgical wounds, and showed longer time to heal and higher costs with the intervention involving store-and-forward teleconsultations. ${ }^{21}$ This study was limited by the uneven distribution of severity and type of wounds among groups, 
which may have biased both effectiveness and cost analyses: groups A and C had larger wounds at the start (262.3 and $153.8 \mathrm{~cm}^{3}$, respectively, and $75.5 \mathrm{~cm}^{3}$ in the control group) and a higher frequency of pressure ulcers, and group A had a higher proportion of patients with more severe disease.

Thirteen out of the 15 studies which assessed clinical outcomes used the asynchronous mode, reflecting that this is the mostly used modality in clinical practice. However, all of them were performed in high income countries. Interventions involving teleassistance may have a similar benefit in developing countries, but, considering the lower socioeconomic and educational level, it is not possible to assure that the impact of educational teledermatology strategies would be similar. Taking into account that those countries would benefit the most from teledermatology interventions, as access to specialized health care is usually impaired, it is important to further study the impact of the intervention in this context.

It is important to mention that, as stated by Zarchi et al, ${ }^{26}$ telemedicine is not a treatment by itself. "It is an operatordependent modality, and its success is determined by the quality, consistency, frequency, and manageability of the therapeutic recommendations provided, the context and setting it is used in, and its acceptance by those it is intended to serve." These facts, along with the methodological quality of included studies, must be carefully examined to prevent erroneous conclusions being drawn. In some studies, there is the possibility of bias toward motivation and technology acceptance, ${ }^{13,23}$ selection of certain groups of patients, ${ }^{23,24}$ as well as high drop out rates, ${ }^{22}$ which may influence the generalizability of the findings. In other cases, teledermatology intervention included an expert with a high level of expertise, that may not be representative of other dermatologists who work with teledermatology interventions. ${ }^{20}$

The main limitations observed in accuracy studies were that FTF examinations and the tele-examinations were performed by the same dermatologist or by the same team of dermatologists. ${ }^{29,32,33}$ Even when there were different examiners, there was substantial difference of experience in the area between them. ${ }^{30}$ The subjective evaluation measures used in the assessment of the lesions in one of the studies led to a large variability of results and it limited the analysis. ${ }^{27}$ Also, the teledermatologists did not analyze the complete history of the patients or were not able to ask patients for more information in some studies, and this might have led to misdiagnoses in teleconsultations. ${ }^{31,32}$ Studies that assessed clinical outcomes included only certain skin conditions, as previously mentioned. Adequately powered studies for subgroups of skin conditions (for example, for patients with rashes, neoplasms, or autoimmune disease) are needed.

\section{Challenges}

Teledermatology has a promising future, but there are some challenges that need to be addressed for further implementation of these services, to provide sustainability and scale up.

Although different studies support cost savings when compared to conventional care, and the perspective of even greater cost reduction as economics improves with higher teledermatology usage,${ }^{53-55}$ lack of policies for funding and reimbursement is still an important barrier for teledermatology implementation in many countries.

Certain skin conditions may not be suitable for teledermatology; for example, skin conditions that require palpation for an accurate diagnosis or lesions in hair-bearing area. ${ }^{15}$ Additionally, it is not possible to perform full-body skin examinations, ${ }^{56}$ and some authors have reported that relying on teledermatology to assess pigmented lesions may lead to under-detection of melanoma by general practitioners. ${ }^{35,57}$

Therefore, teledermatology will not completely replace FTF consultations. Instead, it can be useful as a triage tool, to qualify which patients really need FTF specialized care and help to define the priority in which this care should be delivered. There are examples of heterogeneous distributions of dermatologists all over the world, even in developed countries. In USA, for example, there is a concentration of dermatologists in urban areas despite the absence of professionals to assist patients in rural regions. ${ }^{58}$

Another important aspect arises when analyzing teledermatology interventions between doctors and patients. These kinds of interventions are not regulated in many countries, which may cause issues in the implementation of telemedicine such as guarantee of patients and providers' rights or liabilities and the boundaries of assistance. ${ }^{59}$ Additionally, studies in which those strategies were investigated demonstrated that patients perceived them as less reliable when compared to usual care. FTF consultations enhance the possibility of bonding and can create a trustworthy environment between the health practitioner and the patient. ${ }^{16}$

With regard to technical issues, Information and Communication Technologies Facts \& Figures 2016 reported that the Internet penetration rate is $81 \%$ in developed countries, compared with $40 \%$ in developing countries and $15 \%$ in the least developed countries. These data represent a major challenge to telehealth, considering that those countries with low rates of Internet users would be the most benefited 
Table I Diagnostic reliability studies quality assessment using QAREL checklist

\begin{tabular}{|c|c|c|c|c|c|}
\hline \multirow[t]{2}{*}{ Author, year } & Item I & Item 2 & Item 3 & Item 4 & Item 5 \\
\hline & $\begin{array}{l}\text { Was the sample } \\
\text { of subjects } \\
\text { representative? }\end{array}$ & $\begin{array}{l}\text { Were the raters } \\
\text { representative? }\end{array}$ & $\begin{array}{l}\text { Were raters } \\
\text { blinded to the } \\
\text { findings of other } \\
\text { raters? }\end{array}$ & $\begin{array}{l}\text { Were raters } \\
\text { blinded to } \\
\text { their own prior } \\
\text { findings? }\end{array}$ & $\begin{array}{l}\text { Were raters } \\
\text { blinded to } \\
\text { the results of } \\
\text { the reference } \\
\text { standard? }\end{array}$ \\
\hline
\end{tabular}

\begin{tabular}{|c|c|c|c|c|c|}
\hline Barbieri et al, $2014^{36}$ & Yes & Yes & Yes & Yes & Yes \\
\hline Chung et al, $2007^{37}$ & Yes & Yes & Yes & Unclear & Yes \\
\hline Di Stefani et al, $2007^{38}$ & Yes & Yes & Yes & $\mathrm{n} / \mathrm{a}$ & Yes \\
\hline Fabbrocini et al, $2008^{39}$ & Yes & Yes & Yes & $\mathrm{n} / \mathrm{a}$ & Yes \\
\hline Ferrer et al, $2009^{40}$ & Yes & Yes & Yes & $\mathrm{n} / \mathrm{a}$ & Yes \\
\hline Fruhauf et al, $2010^{41}$ & Yes & Yes & Yes & $\mathrm{n} / \mathrm{a}$ & Yes \\
\hline Heffner et al, $2009^{42}$ & Yes & Yes & Yes & $\mathrm{n} / \mathrm{a}$ & Yes \\
\hline Hill et al, $2009^{43}$ & Yes & Yes & Yes & $\mathrm{n} / \mathrm{a}$ & $\mathrm{n} / \mathrm{a}$ \\
\hline Karlsson et al, $2015^{44}$ & Yes & Yes & Yes & Unclear & $\mathrm{n} / \mathrm{a}$ \\
\hline Lamel et al, $2012^{45}$ & Yes & Yes & Yes & $\mathrm{n} / \mathrm{a}$ & Yes \\
\hline Nami et al, $2015^{46}$ & Yes & Yes & Unclear & $\mathrm{n} / \mathrm{a}$ & Yes \\
\hline Osei-tutu et al, $2013^{47}$ & Yes & Yes & Yes & $\mathrm{n} / \mathrm{a}$ & $\mathrm{n} / \mathrm{a}$ \\
\hline Paradela-de-la-Morena et al, $2015^{48}$ & Yes & Yes & No & Unclear & $\mathrm{n} / \mathrm{a}$ \\
\hline Rennekampff et al, $2015^{49}$ & Yes & Yes & Unclear & $\mathrm{n} / \mathrm{a}$ & $\mathrm{n} / \mathrm{a}$ \\
\hline Rios-Yuil et al, $2012^{50}$ & Yes & Yes & Unclear & No & Yes \\
\hline Romero Aguilera et al, $2014^{51}$ & Yes & Yes & Yes & No & Yes \\
\hline Romero et al, $2010^{7}$ & Yes & Yes & Yes & No & Yes \\
\hline Vano-Galvan et al, $201 \mathrm{I}^{52}$ & Yes & Yes & Unclear & $\mathrm{n} / \mathrm{a}$ & Yes \\
\hline Wu et al, $2015^{5}$ & Yes & Yes & Yes & $\mathrm{n} / \mathrm{a}$ & Yes \\
\hline
\end{tabular}

Abbreviations: n/a, not applicable; QAREL, Quality Appraisal of Reliability Studies.

of teleassistance. On the other hand, it also reported that $95 \%$ of the global population lives in areas covered by a basic $2 \mathrm{G}$ mobile-cellular network and the number of users of advanced mobile-broadband networks continue to grow, having reached 3.6 billion at the end of $2016 .{ }^{60}$ Therefore, mobile technology may make a broader expansion of e-health possible.

Another important aspect is that the system should be simple enough to prevent telemedicine tasks from demanding much of the time of the professionals' workload. Ideally, teledermatology systems should be integrated with electronic medical records, but that is still a challenge.

Proper training should be given to health care professionals to collect patients' data and take good quality pictures of the lesion. The accuracy of telediagnosis is directly related to the image quality, and this was an issue in many of the studies analyzed in this review, some of them pointing up to $18 \%$ of poor quality images. ${ }^{46,51,61}$ It is important to consider that different photography techniques may be needed. In some cases, the distribution of wounds on a patient's body may be more important than close-up details of a single wound, for example, in patients with psoriasis, while detailed close-ups and dermatoscopic images of certain lesions may be critical for correct diagnosis, for example, of a pigmented lesion. ${ }^{62}$ Health care professionals have to be properly trained to send information correctly. In many health settings, the turnover of employees is significant and these places need special programs of continuous training for the new professionals. ${ }^{20}$

\section{Conclusion}

The evidence to date indicates that, overall, teledermatology has good performance in comparison to conventional consultations for diagnostic agreement and diagnostic accuracy. Addtionally, evidence suggests there is no difference in clinical outcomes with teledermatology in most cases, but adequately powered studies for subgroups of skin conditions are needed.

\section{Acknowledgments}

This study was funded by Conselho Nacional de Desenvolvimento Científico e Tecnológico - CNPq (JAQO, grant number 380072/2017-3; LDR, grant number 110643/20178) and Fundação de Amparo à Pesquisa do Estado de Minas Gerais - FAPEMIG (MVRSS, grant number 6617/2016-01). 


\begin{tabular}{|c|c|c|c|c|c|c|c|c|c|}
\hline Item 6 & Item 7 & Item 8 & Item 9 & Item 10 & Item I I & Sum & nary & & \\
\hline $\begin{array}{l}\text { Were raters } \\
\text { blinded } \\
\text { to clinical } \\
\text { information } \\
\text { that was not } \\
\text { intended to be } \\
\text { provided? }\end{array}$ & $\begin{array}{l}\text { Were raters } \\
\text { blinded to } \\
\text { additional } \\
\text { cues? }\end{array}$ & $\begin{array}{l}\text { Was the } \\
\text { order of } \\
\text { examination } \\
\text { varied? }\end{array}$ & $\begin{array}{l}\text { Was the } \\
\text { time interval } \\
\text { between } \\
\text { repeated } \\
\text { measurements } \\
\text { compatible } \\
\text { with the } \\
\text { stability? }\end{array}$ & $\begin{array}{l}\text { Was the } \\
\text { test applied } \\
\text { correctly and } \\
\text { interpreted } \\
\text { appropriately? }\end{array}$ & $\begin{array}{l}\text { Were } \\
\text { appropriate } \\
\text { statistical } \\
\text { measures of } \\
\text { agreement } \\
\text { used? }\end{array}$ & Yes & No & Unclear & n/a \\
\hline Yes & $\mathrm{n} / \mathrm{a}$ & No & Yes & Yes & Yes & 9 & I & 0 & I \\
\hline Yes & Unclear & No & Unclear & Yes & No & 6 & 2 & 3 & 0 \\
\hline Unclear & Unclear & No & Yes & Yes & Yes & 7 & I & 2 & I \\
\hline Yes & Yes & No & Yes & Yes & Yes & 9 & I & 0 & I \\
\hline Yes & Yes & No & Yes & Yes & Yes & 9 & I & 0 & I \\
\hline Yes & Yes & No & Yes & Yes & Yes & 9 & I & 0 & I \\
\hline Yes & Yes & No & Yes & Yes & Yes & 9 & 1 & 0 & I \\
\hline Yes & Yes & Yes & Yes & Yes & Yes & 9 & 0 & 0 & 2 \\
\hline Yes & Yes & $\mathrm{n} / \mathrm{a}$ & Yes & Yes & Yes & 8 & 0 & I & 2 \\
\hline Yes & Yes & No & Yes & Yes & Yes & 9 & I & 0 & I \\
\hline Yes & Yes & No & Yes & Yes & Yes & 8 & I & I & I \\
\hline Yes & Yes & No & Unclear & Yes & No & 7 & 1 & I & 2 \\
\hline Yes & No & No & Yes & Yes & Yes & 6 & 2 & I & I \\
\hline Yes & Yes & No & Yes & Yes & Yes & 7 & 1 & I & 2 \\
\hline Yes & Unclear & No & Yes & Yes & Yes & 7 & 2 & 2 & 0 \\
\hline Yes & Yes & No & Yes & Yes & No & 8 & 3 & 0 & 0 \\
\hline Yes & Yes & No & Yes & Yes & No & 8 & 3 & 0 & 0 \\
\hline Unclear & Unclear & No & Yes & Yes & No & 6 & I & 3 & I \\
\hline Yes & Yes & $\mathrm{n} / \mathrm{a}$ & Yes & Yes & Yes & 9 & 0 & 0 & 2 \\
\hline
\end{tabular}

\section{Disclosure}

The authors report no conflicts of interest in this work.

\section{References}

1. Miot HA, Paixão MP, Wen CL. Teledermatologia: passado, presente e futuro. An Bras Dermatol. 2005;80:523-532. Portuguese.

2. Jacobson CC, Resneck JS Jr, Kimball AB. Generational differences in practice patterns of dermatologists in the United States: implications for workforce planning. Arch Dermatol. 2004;140(12):1477-1482.

3. Assis TG, Palhares DM, Alkmim MB, Marcolino MS. Teledermatology for primary care in remote areas in Brazil. $J$ Telemed Telecare. 2013;19(8):494-495.

4. Maguiness S, Searles GE, From L, Swiggum S. The Canadian Dermatology Workforce Survey: implications for the future of Canadian dermatology - who will be your skin expert? J Cutan Med Surg. 2004;8(3): 141-147.

5. Wu X, Oliveria SA, Yagerman S, et al. Feasibility and efficacy of patient-initiated mobile teledermoscopy for short-term monitoring of clinically atypical nevi. JAMA Dermatol. 2015;151(5):489-496.

6. Borve A, Dahlen Gyllencreutz J, Terstappen K, et al. Smartphone teledermoscopy referrals: a novel process for improved triage of skin cancer patients. Acta Derm Venereol. 2015;95(2):186-190.

7. Romero G, Sanchez P, Garcia M, Cortina P, Vera E, Garrido JA. Randomized controlled trial comparing store-and-forward teledermatology alone and in combination with web-camera videoconferencing. Clin Exp Dermatol. 2010;35(3):311-317.

8. Higgins J, Green S, editors. Cochrane Handbook for Systematic Reviews of Interventions Version 5.1.0 [updated March 2011]. The Cochrane Collaboration; 2011. Available from: http://handbook.cochrane.org. Accessed May 1, 2017.
9. Whiting PF, Rutjes AW, Westwood ME, et al. QUADAS-2: a revised tool for the quality assessment of diagnostic accuracy studies. Ann Intern Med. 2011;155(8):529-536.

10. Lucas NP, Macaskill P, Irwig L, Bogduk N. The development of a quality appraisal tool for studies of diagnostic reliability (QAREL). J Clin Epidemiol. 2010;63(8):854-861.

11. Armstrong AW, Johnson MA, Lin S, Maverakis E, Fazel N, Liu FT. Patient-centered, direct-access online care for management of atopic dermatitis: a randomized clinical trial. JAMA Dermatol. 2015;151(2): 154-160.

12. Balato N, Megna M, Di Costanzo L, Balato A, Ayala F. Educational and motivational support service: a pilot study for mobile-phone-based interventions in patients with psoriasis. Br J Dermatol. 2013;168(1): 201-205.

13. Bergmo TS, Wangberg SC, SchopfTR, Solvoll T. Web-based consultations for parents of children with atopic dermatitis: results of a randomized controlled trial. Acta Paediatr. 2009;98(2):316-320.

14. Bundy C, Pinder B, Bucci S, Reeves D, Griffiths CE, Tarrier N. A novel, web-based, psychological intervention for people with psoriasis: the electronic Targeted Intervention for Psoriasis (eTIPs) study. $\mathrm{Br} \mathrm{J}$ Dermatol. 2013;169(2):329-336.

15. Chambers CJ, Parsi KK, Schupp C, Armstrong AW. Patient-centered online management of psoriasis: a randomized controlled equivalency trial. J Am Acad Dermatol. 2012;66(6):948-953.

16. Fruhauf J, Krock S, Quehenberger F, et al. Mobile teledermatology helping patients control high-need acne: a randomized controlled trial. J Eur Acad Dermatol Venereol. 2015;29(5):919-924.

17. Oostveen AM, Beulens CA, van de Kerkhof PC, de Jong EM, Seyger MM. The effectiveness and safety of short-contact dithranol therapy in paediatric psoriasis: a prospective comparison of regular day care and day care with telemedicine. Br J Dermatol. 2014;170(2):454-457. 
18. Pak H, Triplett CA, Lindquist JH, Grambow SC, Whited JD. Storeand-forward teledermatology results in similar clinical outcomes to conventional clinic-based care. J Telemed Telecare. 2007;13(1): $26-30$.

19. Seghers AC, Seng KH, Chio MT, Chia E, Ng SK, Tang MB. A prospective study on the use of teledermatology in psychiatric patients with chronic skin diseases. Australas J Dermatol. 2015;56(3):170-174.

20. Stern A, Mitsakakis N, Paulden M, et al. Pressure ulcer multidisciplinary teams via telemedicine: a pragmatic cluster randomized stepped wedge trial in long term care. BMC Health Serv Res. 2014;14:83.

21. Terry M, Halstead LS, O'Hare P, et al. Feasibility study of home care wound management using telemedicine. Adv Skin Wound Care. 2009;22(8):358-364.

22. van Os-Medendorp H, Koffijberg H, Eland-de Kok PC, et al. E-health in caring for patients with atopic dermatitis: a randomized controlled cost-effectiveness study of internet-guided monitoring and online selfmanagement training. Br J Dermatol. 2012;166(5):1060-1068.

23. Watson AJ, Bergman H, Williams CM, Kvedar JC. A randomized trial to evaluate the efficacy of online follow-up visits in the management of acne. Arch Dermatol. 2010;146(4):406-411.

24. Whited JD, Warshaw EM, Edison KE, et al. Effect of store and forward/ teledermatology on quality of life: a randomized controlled trial. JAMA Dermatol. 2013;149(5):584-591.

25. Whited JD, Warshaw EM, Kapur K, et al. Clinical course outcomes for store and forward teledermatology versus conventional consultation: a randomized trial. J Telemed Telecare. 2013;19(4):197-204.

26. Zarchi K, Haugaard VB, Dufour DN, Jemec GB. Expert advice provided through telemedicine improves healing of chronic wounds: prospective cluster controlled study. J Invest Dermatol. 2015;135(3):895-900.

27. Baumeister T, Weistenhofer W, Drexler H, Kutting B. Prevention of work-related skin diseases: teledermatology as an alternative approach in occupational screenings. Contact Dermatitis. 2009;61(4): 224-230.

28. Maier T, Kulichova D, Schotten K, et al. Accuracy of a smartphone application using fractal image analysis of pigmented moles compared to clinical diagnosis and histological result. J Eur Acad Dermatol Venereol. 2015;29(4):663-667.

29. Manahan MN, Soyer HP, Loescher LJ, et al. A pilot trial of mobile, patientperformed teledermoscopy. Br J Dermatol. 2015;172(4):1072-1080.

30. Rao BK, Mateus R, Wassef C, Pellacani G. In vivo confocal microscopy in clinical practice: comparison of bedside diagnostic accuracy of a trained physician and distant diagnosis of an expert reader. J Am Acad Dermatol. 2013;69(6):e295-e300.

31. Shin H, Kim DH, Ryu HH, Yoon SY, Jo SJ. Teledermatology consultation using a smartphone multimedia messaging service for common skin diseases in the Korean army: a clinical evaluation of its diagnostic accuracy. J Telemed Telecare. 2014;20(2):70-74.

32. Tan E, Yung A, Jameson M, Oakley A, Rademaker M. Successful triage of patients referred to a skin lesion clinic using teledermoscopy (IMAGE IT trial). Br J Dermatol. 2010;162(4):803-811.

33. Ishioka P, Tenorio JM, Lopes PR, et al. A comparative study of teledermatoscopy and face-to-face examination of pigmented skin lesions. J Telemed Telecare. 2009;15(5):221-225.

34. Warshaw EM, Lederle FA, Grill JP, et al. Accuracy of teledermatology for nonpigmented neoplasms. J Am Acad Dermatol. 2009;60(4):579-588.

35. Warshaw EM, Lederle FA, Grill JP, et al. Accuracy of teledermatology for pigmented neoplasms. J Am Acad Dermatol. 2009;61(5):753-765.

36. Barbieri JS, Nelson CA, James WD, et al. The reliability of teledermatology to triage inpatient dermatology consultations. JAMA Dermatol. 2014;150(4):419-424.

37. Chung P, Yu T, Scheinfeld N. Using cellphones for teledermatology, a preliminary study. Dermatol Online J. 2007;13(3):2.

38. Di Stefani A, Zalaudek I, Argenziano G, Chimenti S, Soyer HP. Feasibility of a two-step teledermatologic approach for the management of patients with multiple pigmented skin lesions. Dermatol Surg. 2007;33(6):686-692.
39. Fabbrocini G, Balato A, Rescigno O, Mariano M, Scalvenzi M, Brunetti B. Telediagnosis and face-to-face diagnosis reliability for melanocytic and non-melanocytic 'pink' lesions. $J$ Eur Acad Dermatol Venereol. 2008;22(2):229-234.

40. Ferrer RT, Bezares AP, Manes AL, et al. Fiabilidad diagnóstica de una consulta de teledermatología asíncrona. [Diagnostic reliability of an asynchronous teledermatology consultation]. Aten Primaria. 2009;41(10):552-557. Spanish.

41. Fruhauf J, Schwantzer G, Ambros-Rudolph CM, et al. Pilot study using teledermatology to manage high-need patients with psoriasis. Arch Dermatol. 2010;146(2):200-201.

42. Heffner VA, Lyon VB, Brousseau DC, Holland KE, Yen K. Store-andforward teledermatology versus in-person visits: a comparison in pediatric teledermatology clinic. J Am Acad Dermatol. 2009;60(6):956-961.

43. Hill ML, Cronkite RC, Ota DT, Yao EC, Kiratli BJ. Validation of home telehealth for pressure ulcer assessment: a study in patients with spinal cord injury. J Telemed Telecare. 2009;15(4):196-202.

44. Karlsson MA, Lindelof B, Wahlgren CF, Wiklund K, Rodvall Y. Mobile teledermatology is a valid method to estimate prevalence of melanocytic naevi in children. Acta Derm Venereol. 2015;95(3):303-306.

45. Lamel SA, Haldeman KM, Ely H, Kovarik CL, Pak H, Armstrong AW. Application of mobile teledermatology for skin cancer screening. $J \mathrm{Am}$ Acad Dermatol. 2012;67(4):576-581.

46. Nami N, Massone C, Rubegni P, Cevenini G, Fimiani M, HofmannWellenhof R. Concordance and time estimation of store-and-forward mobile teledermatology compared to classical face-to-face consultation. Acta Derm Venereol. 2015;95(1):35-39.

47. Osei-tutu A, Shih T, Rosen A, et al. Mobile teledermatology in Ghana: sending and answering consults via mobile platform. J Am Acad Dermatol. 2013;69(2):e90-e91.

48. Paradela-De-La-Morena S, Fernandez-Torres R, Martinez-Gomez W, Fonseca-Capdevila E. Teledermatology: diagnostic reliability in 383 children. Eur J Dermatol. 2015;25(6):563-569.

49. Rennekampff HO, Fimmers R, Metelmann HR, Schumann H, Tenenhaus M. Reliability of photographic analysis of wound epithelialization assessed in human skin graft donor sites and epidermolysis bullosa wounds. Trials. 2015;16:235.

50. Rios-Yuil JM. Correlación del Teleateneo con el Ateneo presencial de Dermatología en el diagnóstico de las patologías cutáneas. [Correlation between face-to-face assessment and telemedicine for the diagnosis of skin disease in case conferences]. Actas Dermosifiliogr. 2012;103(2):138-143. Spanish.

51. Romero Aguilera G, Cortina de la Calle P, Vera Iglesias E, Sanchez Caminero P, Garcia Arpa M, Garrido Martin JA. Interobserver reliability of store-and-forward teledermatology in a clinical practice setting. Actas Dermosifiliogr. 2014;105(6):605-613.

52. Vano-Galvan S, Hidalgo A, Aguayo-Leiva I, et al. Teledermatología diferida: análisis de validez en una serie de 2.000 observaciones. [Storeand-forward teledermatology: assessment of validity in a series of 2000 observations]. Actas Dermosifiliogr. 2011;102(4):277-283. Spanish.

53. Armstrong AW, Dorer DJ, Lugn NE, Kvedar JC. Economic evaluation of interactive teledermatology compared with conventional care. Telemed $J$ E Health. 2007;13(2):91-99.

54. Byamba K, Syed-Abdul S, Garcia-Romero M, et al. Mobile teledermatology for a prompter and more efficient dermatological care in rural Mongolia. Br J Dermatol. 2015;173(1):265-267.

55. Pak HS, Datta SK, Triplett CA, Lindquist JH, Grambow SC, Whited JD. Cost minimization analysis of a store-and-forward teledermatology consult system. Telemed J E Health. 2009;15(2):160-165.

56. Armstrong AW, Kwong MW, Ledo L, Nesbitt TS, Shewry SL. Practice models and challenges in teledermatology: a study of collective experiences from teledermatologists. PloS One. 2011;6(12):e28687.

57. Aldridge RB, Naysmith L, Ooi ET, Murray CS, Rees JL. The importance of a full clinical examination: assessment of index lesions referred to a skin cancer clinic without a total body skin examination would miss one in three melanomas. Acta Derm Venereol. 2013;93(6):689-692. 
58. Coates SJ, Kvedar J, Granstein RD. Teledermatology: from historical perspective to emerging techniques of the modern era. Part I: history, rationale, and current practice. JAm Acad Dermatol. 2015;72(4):563-574.

59. Raposo VL. Telemedicine: the legal framework (or the lack of it) in Europe. GMS Health Technol Assess. 2016;12:Doc03.

60. International Telecommunication Union. Measuring the Information Society Report 2016. Geneva: ITU; 2016.
61. Tandjung R, Badertscher N, Kleiner N, et al. Feasibility and diagnostic accuracy of teledermatology in Swiss primary care: process analysis of a randomized controlled trial. J Eval Clin Pract. 2015;21(2): 326-331.

62. Levin YS, Warshaw EM. Teledermatology: a review of reliability and accuracy of diagnosis and management. Dermatol Clin. 2009;27(2):163-176.

\section{Publish your work in this journal}

Smart Homecare Technology and TeleHealth is an international, peer-reviewed open access online journal publishing original research, reviews, editorials and commentaries on the application of technology to support people and patients at home and in assisted living centers to optimize healthcare and management resources. Specific topics in the journal include: Development and application of devices within the home and embedded in appliances; Healthcare provider communication and education tools; and drug ordering and adherence. The manuscript management system is completely online and includes a very quick and fair peer-review system, which is all easy to use. Visit http://www.dovepress.com/ testimonials.php to read real quotes from published authors.

Submit your manuscript here: https://www.dovepress.com/smart-homecare-technology-and-telehealth-journal 